\title{
Consumption Frequency of Foods Away from Home Linked with Higher Body Mass Index and Lower Fruit and Vegetable Intake among Adults: A Cross-Sectional Study
}

\author{
Rebecca A. Seguin, ${ }^{1}$ Anju Aggarwal, ${ }^{2}$ Francoise Vermeylen, ${ }^{3}$ and Adam Drewnowski ${ }^{4}$ \\ ${ }^{1}$ Division of Nutritional Sciences, Cornell University, 412 Savage Hall, Ithaca, NY 14853, USA \\ ${ }^{2}$ Center for Public Health Nutrition, University of Washington, 330 Raitt Hall, Seattle, WA 98195, USA \\ ${ }^{3}$ Division of Nutritional Sciences, Cornell University, B07 Savage Hall, Ithaca, NY 14853, USA \\ ${ }^{4}$ Nutritional Sciences, University of Washington, 305 Raitt Hall, Seattle, WA 98195, USA \\ Correspondence should be addressed to Rebecca A. Seguin; rs946@cornell.edu
}

Received 11 September 2015; Accepted 7 December 2015

Academic Editor: How-Ran Guo

Copyright (C) 2016 Rebecca A. Seguin et al. This is an open access article distributed under the Creative Commons Attribution License, which permits unrestricted use, distribution, and reproduction in any medium, provided the original work is properly cited.

\begin{abstract}
Introduction. Consumption of foods prepared away from home (FAFH) has grown steadily since the 1970s. We examined the relationship between FAFH and body mass index (BMI) and fruit and vegetable (FV) consumption. Methods. Frequency of FAFH, daily FV intake, height and weight, and sociodemographic data were collected using a telephone survey in 2008-2009. Participants included a representative sample of 2,001 adult men and women (mean age $54 \pm 15$ years) residing in King County, WA, with an analytical sample of 1,570. Frequency of FAFH was categorized as 0-1,2-4, or 5+ times per week. BMI was calculated from self-reported height and weight. We examined the relationship between FAFH with FV consumption and BMI using multivariate models. Results. Higher frequency of FAFH was associated with higher BMI, after adjusting for age, income, education, race, smoking, marital status, and physical activity (women: $p=0.001$; men: $p=0.003$ ). There was a negative association between frequency of FAFH and FV consumption. FAFH frequency was significantly $(p<0.001)$ higher among males than females $(43.1 \%$ versus $54.0 \%$ eating out $0-1$ meal per week, resp.). Females reported eating significantly $(p<0.001)$ more FV than males. Conclusion. Among adults, higher frequency of FAFH was related to higher BMI and less FV consumption.
\end{abstract}

\section{Introduction}

There has been a notable shift in eating culture in the past 40 years. Since the late 1970s, consumption of foods prepared outside the home has steadily grown, from one-sixth to almost one-third of an individual's daily dietary intake [1-4]. A 2012 analysis of 2007-2008 National Health and Nutrition Examination Survey (NHANES) data found that $41 \%$ of adults consumed foods and/or beverages from fast food-type restaurants and $27 \%$ from full-service restaurants during the previous 24 hours [2]. With fewer meals being prepared at home, the overall quantity of calories has increased while nutritional quality has declined.

Not surprisingly, individuals who consume more FAFH are reported to have poorer diet quality. Higher fruit and vegetable intake is associated with better dietary quality $[5,6]$, and some studies have found an inverse relationship between frequency of fast food use and daily servings or meal density of fruit and vegetables [7-12]. The Healthy Eating Index (HEI) is a measure of diet quality, with total fruit and total vegetable intake as two of the main components of this composite measure [13]. Economic Research Service Reports using the 1994-96 Continuing Survey of Food Intakes by Individuals (CSFII) and 2003-04 NHANES data found that one meal away from home lowered the daily HEI score enough to shift the average adult's diet quality from a classification of fair to poor $[12,14]$. Another study using the CSFII 1994-96 data reported that more days of fast food consumption resulted in increased energy and macronutrient intakes and decreased micronutrient density [15]. More specifically, eating fast food 
was associated with lower intakes of vitamin A, carotene, vitamin $\mathrm{C}$, calcium, and magnesium, high amounts of nondiet carbonated soft drinks, and insignificant amounts of fruit [15]. Other studies have found that those who consume FAFH more frequently have higher intakes of total energy, total fat, saturated fat, cholesterol, sodium, sugar-sweetened beverages, and sugar and lower intakes of fiber and some micronutrients [10, 14-19].

Cross-sectional and prospective studies have also found that frequent FAFH consumption is associated with higher body mass index (BMI) and percent body fat as well as increased risk for overweight/obesity, cardiometabolic risk factors, and type 2 diabetes [7, 10, 15, 16, 19-40]. The Coronary Artery Risk Development in Young Adults (CARDIA) study found that change in fast-food frequency over 15 years was directly associated with changes in body weight [41]. Similarly, a national study of Australian young adults reported that, after adjusting for confounding variables including age, leisure time physical activity, TV viewing, and employment status, consuming takeaway food twice a week or more was associated with a $31 \%$ higher prevalence of moderate abdominal obesity in men and a 25\% higher prevalence in women, compared to those who ate takeaway food less than twice a week [39]. Many of the studies linking FAFH with overweight and obesity were conducted with children, adolescents, or young adults [9, 10, 28, 29, 34, 36-39, 42-44].

The shift that has occurred in consumption frequency of FAFH has had important implications in terms of diet quality, including fruit and vegetable intake, and obesity. This cross-sectional study aimed to examine the relationship between FAFH frequency and fruit and vegetable intake as well as the relationship between FAFH frequency and BMI among a representative sample of adult men and women King County, Washington. As most previous studies have focused on younger age groups, the present study fills an important gap in the literature.

\section{Methods}

The Seattle Obesity Study was a cross-sectional study of 2,001 adult male and female residents of King County, Washington. A stratified random sampling scheme was used to ensure a representative sample by income and race/ethnicity. Detailed study methodology has previously been published $[45,46]$ and discussed here briefly. To develop the sampling frame, randomly generated telephone numbers were matched with residential addresses, using commercial database. A prenotification letter was mailed out to alert potential respondents that their household had been randomly selected for this study. Telephone calls were made to every household to randomly select an adult member as a survey respondent. Exclusion criteria were age less than 18 years, discordance between addresses and telephone numbers obtained from the commercial database, and those self-reported by the respondent. After screening for eligibility, study procedures were explained to the potential respondent and a verbal consent was obtained over the phone and formally recorded. A 25-minute telephone survey was then administered to all the participants. A total of 2,001 respondents participated in the telephone survey. The SOS sample was demographically comparable to 2007 Behavioral Risk Factor Surveillance System (BRFSS) and King County Census data. All procedures involving human subjects/patients were approved by The University of Washington Institutional Review Board.

2.1. Frequency of Food Consumption Away from Home $(F A F H)$. Self-reported data on frequency of FAFH was available from 1,976 of 2,001 phone survey respondents. Respondents were asked to report number of meals eaten out each week, including breakfast and lunch. Frequency of FAFH was categorized as $0-1,2-4$, or 5 or more times per week based on the distribution of the data obtained.

2.2. Sociodemographic and Lifestyle Measures. The telephone survey asked a series of questions to collect self-reported data on socioeconomic status (SES) and demographic and lifestyle variables. Annual household income and education were used as the indicators of SES. Income data collected using 9 categories was recombined into three categories for analytical purpose: $<\$ 50,000, \$ 50,000-\$ 100,000$, and $>\$ 100,000$, herein $\$ 50 \mathrm{~K}, \$ 50-\$ 100 \mathrm{~K}$, and $>\$ 100 \mathrm{~K}$. The 6category education variable was recombined into three groups: "high school or less," "some college," and "college graduates or higher." Demographic variables of interest were age, gender, race/ethnicity, and household size. Smoking and physical activity were used as lifestyle indicators. Physical activity was captured using the standard question from BRFSS (Behavioral Risk factor Surveillance System)"During the past month, other than your regular job, did you participate in any physical activity or exercise in your leisure time apart from your work?" For analytical purpose, it was treated as a dichotomous variable: yes/no. The smoking variable was dichotomized into never versus current/former. One thousand six hundred ninety-seven respondents had complete data for the demographic and lifestyle variables.

2.3. Health Outcome Measure: BMI. Self-reported data on weight and height was available from 1,877 survey respondents and was used to compute BMI. BMI was calculated as weight (in kilograms) divided by square of height (in meters).

2.4. Fruit and Vegetable Intake. Standard dietary questions from BRFSS were used to capture the intake of fruits and vegetables, and other foods for the present study. Each respondent was asked to report the frequency of consumption of fruit juices, fruits, green salad, carrots, and other vegetables by per day/week/month or year basis. The reported frequency for each of these items was added together to compute the total fruit and vegetable intake per person per day. Fruit and vegetable intake data were available from 1,937 respondents.

2.5. Statistical Analyses. All statistical analyses were conducted using SPSS 21.0 for Windows (version 2012, IBMSPSS, Inc.). First, univariate descriptive statistics were conducted for each variable (means, standard deviations, and frequencies). Bivariate associations were then examined between frequency of FAFH and each of the sociodemographic variables, BMI, and fruit and vegetable consumption, 
TABLE 1: Sample characteristics of female and male adults in the sample.

\begin{tabular}{|c|c|c|c|c|c|c|}
\hline \multirow[t]{2}{*}{ Variable } & & & \multicolumn{4}{|c|}{ Gender } \\
\hline & \multicolumn{2}{|c|}{ Total } & \multicolumn{2}{|c|}{ Female } & \multicolumn{2}{|c|}{ Male } \\
\hline \multirow[t]{2}{*}{$N$} & \multicolumn{2}{|c|}{1570} & \multicolumn{2}{|c|}{$936(60 \%)$} & \multicolumn{2}{|c|}{$634(40 \%)$} \\
\hline & Mean \pm SD & $n$ & Mean \pm SD & $n$ & Mean \pm SD & $n$ \\
\hline Age & $53.72 \pm 14.64$ & 1570 & $54.00 \pm 14.83$ & 936 & $53.31 \pm 14.34$ & 634 \\
\hline \multirow[t]{3}{*}{ BMI } & $26.56 \pm 5.45$ & 1570 & $26.09 \pm 5.81$ & 936 & $27.25 \pm 4.81$ & 634 \\
\hline & \multicolumn{2}{|c|}{ Total } & \multicolumn{2}{|c|}{ Female } & \multicolumn{2}{|c|}{ Male } \\
\hline & \multicolumn{2}{|c|}{$N(\%)$} & \multicolumn{2}{|c|}{$N(\%)$} & \multicolumn{2}{|c|}{$N(\%)$} \\
\hline \multicolumn{7}{|l|}{ Race } \\
\hline White & \multicolumn{2}{|c|}{$1313(84)$} & \multicolumn{2}{|c|}{$782(84)$} & \multicolumn{2}{|c|}{$531(84)$} \\
\hline Not White & \multicolumn{2}{|c|}{$257(16)$} & \multicolumn{2}{|c|}{$154(17)$} & \multicolumn{2}{|c|}{$103(16)$} \\
\hline \multicolumn{7}{|l|}{ Education } \\
\hline High school & \multicolumn{2}{|c|}{$263(17)$} & \multicolumn{2}{|c|}{$154(17)$} & \multicolumn{2}{|c|}{$109(17)$} \\
\hline Some college & \multicolumn{2}{|c|}{$410(26)$} & \multicolumn{2}{|c|}{$243(26)$} & 167( & \\
\hline College graduate & 897 & & 539( & & 358 & \\
\hline Income & & & & & & \\
\hline$<\$ 50 \mathrm{~K}$ & 617 & & 386( & & 231( & \\
\hline$\$ 50-\$ 100 \mathrm{~K}$ & 540 & & 318 & & 222 & \\
\hline$>\$ 100 \mathrm{~K}$ & 413 & & 232( & & 181( & \\
\hline Marital status & & & & & & \\
\hline Married or member of unmarried couple & 891 & & $521(5$ & & 370 & \\
\hline Divorced/separated/widowed/never married & 679 & & 415( & & 264 & \\
\hline Smoking status & & & & & & \\
\hline Never smoker & 838 & & 527( & & 311( & \\
\hline Former/current smoker & 732 & & 409 & & 323 & \\
\hline Physical activity & & & & & & \\
\hline Yes & 1238 & & 732( & & 506( & \\
\hline No & 332 & & 204( & & 128( & \\
\hline Frequency of FAFH per week (FAFH) & & & & & & \\
\hline $0-1$ & 778 & & 505 & & 273 & \\
\hline $2-4$ & 539 & & 319 & & 220 & \\
\hline $5+$ & 253 & & $112(1$ & & 141( & \\
\hline & Mean \pm SD & $n$ & Mean \pm SD & $n$ & Mean \pm SD & $n$ \\
\hline Fruit and vegetable servings per day & $4.19 \pm 2.13$ & 1570 & $4.45 \pm 2.18$ & 936 & $3.81 \pm 2.01$ & 634 \\
\hline
\end{tabular}

FAFH, foods away from home.

separately for males and females as well as for both genders combined. Chi-square tests of independence or analysis of variance tests, followed by post hoc comparisons, were run to test the association of these demographic variables with FAFH. Finally, General Linear Models (GLM) were used to assess the relationship between BMI and FAFH, and fruit and vegetable consumption and FAFH. The analyses were conducted separately for each gender as well as for both genders combined. The dependent variables were, respectively, BMI and fruit and vegetable consumption. The independent variables tested in the model were FAFH, gender, age, education, income, marital status, physical activity, and smoking. For the model for both genders combined, interaction terms between gender and other relevant independent variables were tested.

\section{Results}

Sample characteristics of the 1570 adults with complete data for all of the above described variables are presented in Table 1. A higher percentage of females participated than males ( $60 \%$ versus $40 \%$, resp.). Mean age of the sample was 53.7. The sample was more likely to be White (84\%), educated (57\% college graduate), and with annual household income of $>\$ 50 \mathrm{~K}(60 \%)$. About half the sample was married $/$ member of an unmarried couple (57\%), and half of the sample never smoked (53\%). Most of the sample reported being physically active outside work (79\%). Half of the sample consumed FAFH 0-1 time per week, with $34 \%$ of the sample consuming 2-4 times per week, and $16 \%$ eating out 5 or more meals per 
week. Average FV consumption was 4.19 servings per day, and the average BMI was 26.6.

Sociodemographic profile of the sample was also observed by gender (Table 1). Females and males were comparable by income, education, race, marital status, and physical activity. However, differences were observed by other variables of interest. Average BMI was much higher among males $\left(27.3 \mathrm{~kg} / \mathrm{m}^{2}\right)$ as compared to females $\left(26.1 \mathrm{~kg} / \mathrm{m}^{2}\right)$. Overall, FAFH frequency was higher among males than females (43\% versus 54\% eating out $0-1$ meal per week, resp.). A significantly higher proportion of males ate out 5 or more meals per week (22\% versus $12 \%$ among females) ( $p$ value $<0.001)$. On average, females reported eating approximately half a serving more of fruits and vegetables per day than males (4.45 versus 3.81 servings per day, resp.; $p<0.001)$.

Bivariate associations between FAFH frequency and key sociodemographic variables are presented in Table 2. Significant bivariate trends were observed in frequency of FAFH with selected sociodemographic variables, health indicators, and FV consumption. Higher frequency of FAFH was associated with being younger in age and higher BMI both among females and males $(p<0.05)$. For example, females with FAFH frequency $5+$ times per week were on average $50 \mathrm{y}$ old as compared to $57 \mathrm{y}$ old for those never or rarely eating out (defined as 0-1 time per week). Higher frequency of FAFH was associated with relatively higher BMI both among females and males. For example, mean BMI was $27.4 \mathrm{~kg} / \mathrm{m}^{2}$ among females with frequency of FAFH $5+$ times/week as compared to $25.8 \mathrm{~kg} / \mathrm{m}^{2}$ among those who never or rarely ate out ( 0 - 1 time per week) $(p<0.05)$. For females, frequency of FAFH was higher among college graduates (15\% with FAFH frequency $5+$ times per week) as compared to those with high school or some college (only 7\%). Similar trends were seen among males (25\% versus 15\%, resp.), although the relationship was not significant. Respondents with higher annual household income had higher frequency of FAFH. For example, among females, $12 \%$ of those with household income of $\$ 50-\$ 100 \mathrm{~K}$ and $20 \%$ of those with income $>\$ 100 \mathrm{~K}$ ate out five or more times per week as compared to only $7 \%$ of those with income $<\$ 50 \mathrm{~K}$. The corresponding numbers among males were $23 \%, 28 \%$, and $17 \%$, respectively.

There were mixed results for the associations between FAFH and fruit and vegetable intake. For example, for males, while there were significant differences between fruit and vegetable intake for those who ate out $0-1$ or 2-4 times per week versus 5 or more times per week, the overall association was not significant $(3.98,3.78$, and $3.53, p$ value $=0.093)$. A similar pattern was observed for females.

No significant differences were observed in frequency of FAFH by race, marital status, or smoking status.

Table 3 shows associations between BMI and frequency of FAFH, separately among females and males as well as for both genders combined, after adjusting for covariates. There were no significant interactions between gender and other relevant independent variables. Among females, frequency of FAFH 5 or more times per week was associated with significantly higher BMI as compared to those who eat out only once per week or never $(\beta=2.19$; $\mathrm{SE}=0.60 ; p$ value $<0.001)$. However,

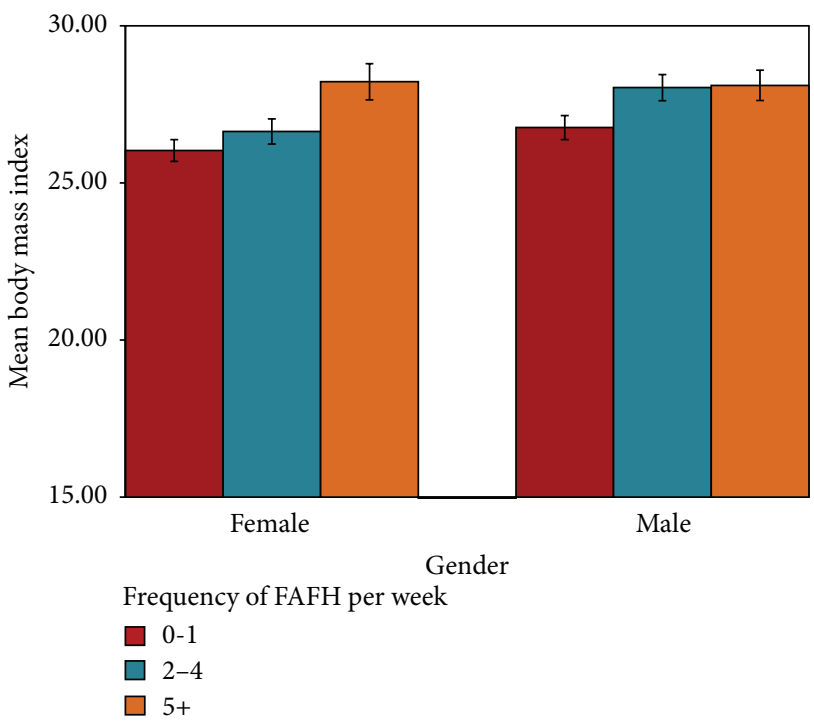

Figure 1: Mean BMI by gender and frequency of foods away from home (FAFH). Mean BMI by gender and frequency of foods away from home (FAFH) after controlling for age, race, gender, education, income, marital status, smoking status, and physical activity.

no significant difference in BMI was observed among females with frequency of FAFH 2-4 times per week as compared to the reference category. Among males, eating out 2-4 times per week and 5 times per week or more were associated with significantly higher $\mathrm{BMI}(\beta=1.27 ; \mathrm{SE}=0.44 ; p$ value $=0.004$ and $\beta=1.34 ; \mathrm{SE}=0.52 ; p$ value $=0.010$, resp.), as compared to those who only eat out only once a week or never. These associations were observed even after adjusting for covariates: income, education, race/ethnicity, marital status, and lifestyle variables (Figure 1).

Significant associations were also observed between key sociodemographic and lifestyle variables and BMI, both among females and males. For example, higher income was associated with significantly lower BMI among females (as compared to the reference category of $<\$ 50 \mathrm{~K}, \beta=1.87, p$ value 0.001 among those with income $\$ 50-\$ 100 \mathrm{~K}$; and $\beta=$ $1.35, p$ value 0.008 among those with income $>\$ 100 \mathrm{~K})$. For males, a significant relation was observed with education. As compared to college graduates, having lower education was associated with higher BMI $(\beta=1.23$, $p$ value: 0.028$)$. Physical activity had a significant negative association with BMI for both females and males (among females, $\beta=2.61, p$ value $\leq$ 0.001 for those who were not physically active outside work; among males, $\beta=1.33, p$ value $=0.006$ ). No other effects were significant in the models. For the models with gender combined, eating out $2-4$ times per week and 5 or more times per week were associated with significantly higher BMI $(\beta=$ $0.97, p$ value $=0.001$ and $\beta=1.88, p$ value $<0.001$, resp.), as compared to those who eat out only once a week or never.

Table 4 displays the multivariate associations between FV consumption and frequency of FAFH, separately for females and males. Among females, those who ate FAFH 2-4 times per week consumed significantly fewer servings 


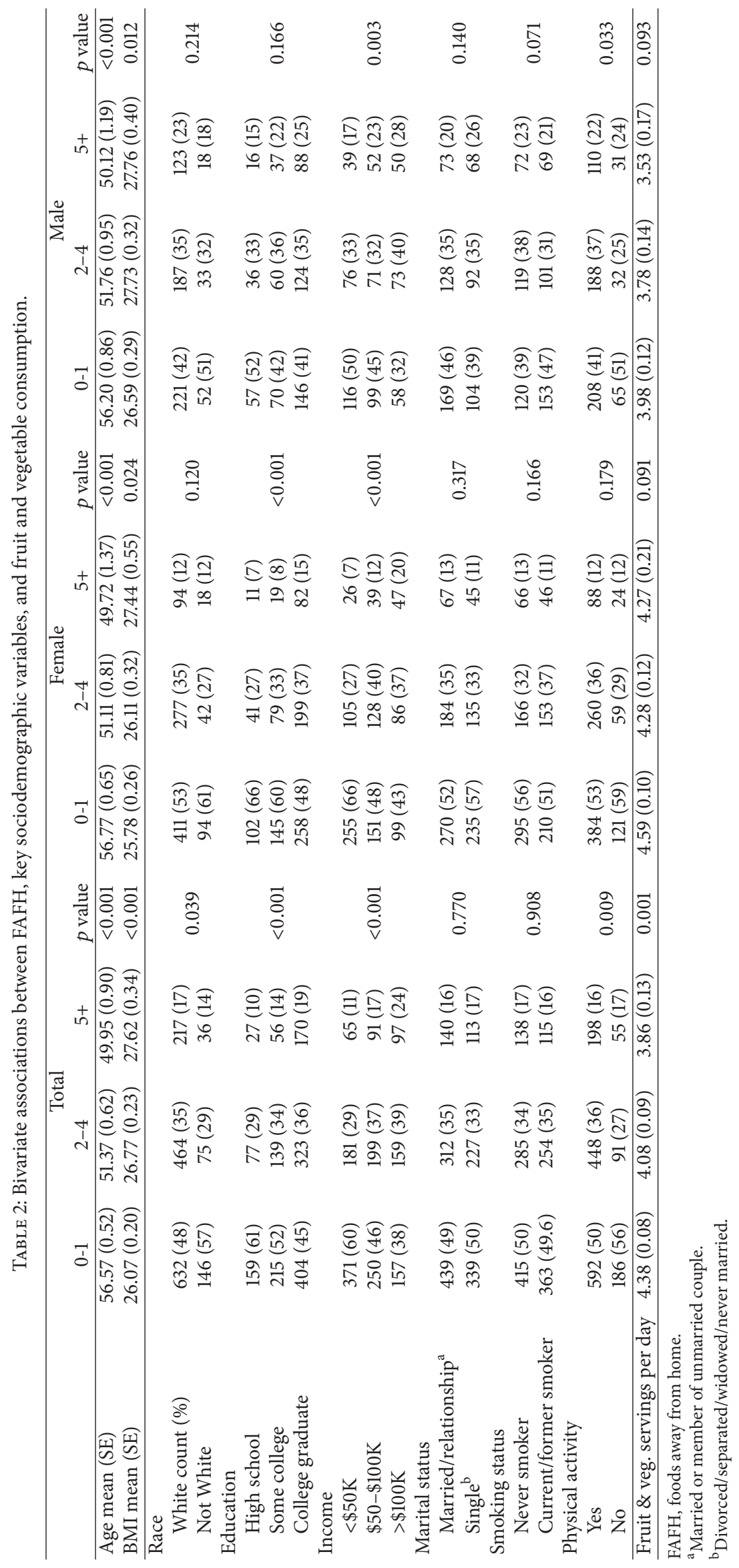


TABLE 3: Multivariate analysis of BMI and frequency of FAFH by gender, adjusted for covariates.

\begin{tabular}{|c|c|c|c|c|c|c|c|c|c|}
\hline \multirow{2}{*}{$\begin{array}{l}\text { Dependent variable: body mass index (BMI) } \\
\text { Parameter }\end{array}$} & \multicolumn{3}{|c|}{ Total } & \multicolumn{3}{|c|}{ Female } & \multicolumn{3}{|c|}{ Male } \\
\hline & $\beta$ & SE & $p$ value & $\beta$ & SE & $p$ value & $\beta$ & SE & $p$ value \\
\hline Intercept & 24.28 & 0.89 & $<0.001$ & 23.27 & 1.18 & $<0.001$ & 25.44 & 1.34 & $<0.001$ \\
\hline Age & 0.01 & 0.01 & 0.314 & 0.01 & 0.02 & 0.406 & 0.01 & 0.02 & 0.550 \\
\hline \multicolumn{10}{|l|}{ Race (ref. = White) } \\
\hline Not White & -0.72 & 0.37 & 0.052 & -0.68 & 0.50 & 0.171 & -0.92 & 0.54 & 0.089 \\
\hline \multicolumn{10}{|l|}{ Education (ref. = college graduate) } \\
\hline High school & 0.68 & 0.40 & 0.090 & 0.13 & 0.56 & 0.811 & 1.24 & 0.56 & 0.028 \\
\hline Some college & 0.22 & 0.33 & 0.514 & 0.05 & 0.45 & 0.918 & 0.41 & 0.47 & 0.384 \\
\hline \multicolumn{10}{|l|}{ Income (ref. $\geq \$ 100 \mathrm{~K}$ ) } \\
\hline$<\$ 50 \mathrm{~K}$ & 1.26 & 0.41 & 0.002 & 1.87 & 0.58 & 0.001 & 0.66 & 0.56 & 0.242 \\
\hline$\$ 50-\$ 100 \mathrm{~K}$ & 0.93 & 0.36 & 0.010 & 1.36 & 0.51 & 0.008 & 0.54 & 0.50 & 0.281 \\
\hline \multicolumn{10}{|l|}{$\begin{array}{l}\text { Marital status (ref. = married or member of } \\
\text { unmarried couple) }\end{array}$} \\
\hline Divorced/separated/widowed/never married & -0.37 & 0.33 & 0.271 & -0.11 & 0.45 & 0.803 & -0.72 & 0.49 & 0.143 \\
\hline \multicolumn{10}{|l|}{ Smoking status (ref. = current/former smoker) } \\
\hline Never smoked & -0.35 & 0.27 & 0.200 & -0.58 & 0.38 & 0.126 & 0.13 & 0.40 & 0.741 \\
\hline \multicolumn{10}{|l|}{ Physical activity (ref. = yes) } \\
\hline No & 2.07 & 0.34 & $<0.001$ & 2.61 & 0.46 & $<0.001$ & 1.33 & 0.48 & 0.006 \\
\hline \multicolumn{10}{|l|}{ Frequency of FAFH per week $($ FAFH $)($ ref. $=0-1)$} \\
\hline $2-4$ & 0.97 & 0.30 & 0.001 & 0.61 & 0.41 & 0.140 & 1.27 & 0.44 & 0.004 \\
\hline $5+$ & 1.88 & 0.40 & $<0.001$ & 2.19 & 0.60 & $<0.001$ & 1.34 & 0.52 & 0.010 \\
\hline
\end{tabular}

FAFH, foods away from home; ref., reference category.

TABLE 4: Multivariate analysis of FV servings per day and frequency of FAFH by gender, adjusted for covariates.

\begin{tabular}{|c|c|c|c|c|c|c|c|c|c|}
\hline \multirow{2}{*}{$\begin{array}{l}\text { Dependent variable: fruit and vegetables } \\
\text { servings/day } \\
\text { Parameter }\end{array}$} & \multicolumn{3}{|c|}{ Total } & \multicolumn{3}{|c|}{ Female } & \multicolumn{3}{|c|}{ Male } \\
\hline & $\beta$ & SE & $p$ value & $\beta$ & SE & $p$ value & $\beta$ & SE & $p$ value \\
\hline Intercept & 3.56 & 0.34 & $<0.001$ & 3.663 & 0.44 & $<0.001$ & 3.54 & 0.55 & $<0.001$ \\
\hline Age & 0.02 & 0.00 & $<0.001$ & 0.018 & 0.01 & 0.001 & 0.01 & 0.01 & 0.065 \\
\hline \multicolumn{10}{|l|}{ Race (ref. $=$ White $)$} \\
\hline Not White & 0.32 & 0.14 & 0.028 & 0.40 & 0.19 & 0.033 & 0.19 & 0.22 & 0.396 \\
\hline \multicolumn{10}{|l|}{ Education (ref. = college graduate) } \\
\hline High school & -0.74 & 0.16 & $<0.001$ & -0.97 & 0.21 & $<0.001$ & -0.37 & 0.23 & 0.105 \\
\hline Some college & -0.61 & 0.13 & $<0.001$ & -0.46 & 0.17 & 0.007 & -0.81 & 0.19 & $<0.001$ \\
\hline \multicolumn{10}{|l|}{ Income (ref. $\geq \$ 100 \mathrm{~K})$} \\
\hline$<\$ 50 \mathrm{~K}$ & 0.27 & 0.16 & 0.095 & 0.31 & 0.22 & 0.157 & 0.20 & 0.23 & 0.384 \\
\hline$\$ 50-\$ 100 \mathrm{~K}$ & 0.45 & 0.14 & 0.001 & 0.53 & 0.19 & 0.006 & 0.36 & 0.20 & 0.079 \\
\hline \multicolumn{10}{|l|}{$\begin{array}{l}\text { Marital status (ref. = married or member of } \\
\text { unmarried couple) }\end{array}$} \\
\hline Divorced/separated/widowed/never married & -0.14 & 0.13 & 0.298 & -0.16 & 0.17 & 0.358 & -0.22 & 0.20 & 0.263 \\
\hline \multicolumn{10}{|l|}{ Smoking status $($ ref. $=$ current $/$ former smoker $)$} \\
\hline Never smoked & -0.04 & 0.11 & 0.740 & -0.08 & 0.14 & 0.565 & -0.10 & 0.16 & 0.540 \\
\hline \multicolumn{10}{|l|}{ Physical activity (ref. = yes) } \\
\hline No & -0.93 & 0.13 & $<0.001$ & -1.04 & 0.17 & $<0.001$ & -0.77 & 0.20 & $<0.001$ \\
\hline \multicolumn{10}{|l|}{ Frequency of FAFH per week $($ FAFH $)($ ref. $=0-1)$} \\
\hline $2-4$ & -0.32 & 0.12 & 0.007 & -0.36 & 0.15 & 0.018 & -0.16 & 0.18 & 0.386 \\
\hline $5+$ & -0.46 & 0.15 & 0.003 & -0.30 & 0.23 & 0.182 & -0.34 & 0.21 & 0.106 \\
\hline
\end{tabular}

FV, fruit and vegetable; FAFH, foods away from home; ref., reference category. 
of fruit and vegetables per day than those who ate out 0 1 time per week $(\beta=-0.36$; $\mathrm{SE}=0.15 ; p$ value $=0.018)$, adjusted for income, education, race/ethnicity, marital status, and lifestyle variables. However, no significant difference in $\mathrm{FV}$ consumption was observed among females who ate FAFH 5 or more times per week compared to those who ate out $0-1$ time per week. Among males, no significant associations were observed between FV consumption and FAFH frequency. There were no significant interactions between gender and other relevant independent variables. For the models with gender combined, eating FAFH 2-4 times per week and 5 or more times per week was associated with significantly less FV consumption $(\beta=-0.32, p$ value $=0.007$ and $\beta=-0.46, p$ value $=0.003$, resp.), compared to eating FAFH 0-1 time per week.

\section{Discussion}

4.1. FAFH and BMI. In the current study, higher frequency of FAFH was associated with higher BMI among both females and males. A 2012 review reported that 7 out of 8 cohort studies found a positive association between the frequency of eating away from home and body weight [23]. Among cross-sectional studies, the same review reported that, of 27 cross-sectional studies, 9 showed no association or a negative association among women and 11 showed no association or a negative association among men [23]. In those studies that found no relationship between FAFH frequency and body weight, the authors of the review suggested that lack of a common definition of the out-of-home eating concept, food intake assessment method, small sample size, and, in a Spanish study, frequency of consumption of food from healthy restaurants versus fast food establishments may have contributed to the lack of association [23].

4.2. Explaining the Relationship between FAFH and BMI. In general, fast foods and FAFH tend to be energy dense. A number of studies have found FAFH to be energy dense, and with higher amounts of total fat and sugar than homeprepared meals $[12,15,47,48]$. Portion sizes at fast food chains and restaurants might be another factor that contributes to unintended consumption of excess energy. Fast food and restaurants portion sizes have increased over the past 30 years. For example, Young and Nestle found that current sizes for French fries, hamburgers, and sodas are 2 to 5 times larger than the original sizes offered [49]. A number of experiments have determined that people eat more when they are served larger portions [50-56]. Energy content and portion size in foods away from home likely contribute to excess energy intake in those who often eat out. This excess energy intake may lead to weight gain, since individuals often do not compensate for consuming larger portions by decreasing caloric intake or increasing physical activity [50, $54,55]$. Overweight individuals may be more affected by large portion sizes than normal weight consumers [57].

Influences on food choice, including the choices to eat out, eat less, or eat more healthful foods, are complex and include food upbringing, family role, health, ethnic identity and traditions, food environment, and resources, including knowledge and skills; time, space, and finances; social networks and supports; and cultural and social skills [58]. Other models of food choice include explanations of value negotiations, weighing sensory perceptions, monetary considerations, health and nutrition beliefs and concerns, convenience, and social relationships [59]. Recent evidence indicates that a greater amount of time spent on home food preparation is associated with more frequent intake of fruits and vegetables $[60,61]$.

4.3. FAFH Frequency and FV Consumption. Although there were mixed results for the associations between FAFH frequency and FV consumption in this study, the findings suggest a negative correlation. Most studies have found eating out to be associated with poor diet quality, including lower consumption of fruits and vegetables [10, 14-19]. A few previous studies found that eating out was associated with higher vegetable consumption $[8,10,62]$. In one of these, the authors suggested the categorization of French fries as a vegetable may have contributed to this finding [8]. Two studies found that eating at full service restaurants was associated with higher vegetable consumption, but eating at burger-and-fries or non-fast food restaurants was not associated or negatively associated with vegetable consumption $[10,62]$. A few studies have found frequency of fruit consumption to be higher among those who ate out more frequently, at least in some subpopulations [62-64]. Befort and colleagues found that, for Black adolescents, fruit intake was positively associated with sit-down, menu-based restaurant use, but this was not the case for White adolescents or for fast food restaurant use [62]. A study of Korean housewives found that, in the middle income class, frequency of fruit consumption was significantly higher with more frequent eating out, but there were no associations in the lower or upper classes [63]. Another Korean study reported that people who ate out more frequently consumed more fruit; the authors noted that this could be explained by Korean restaurants serving fresh fruit as dessert [64].

In the current analysis, eating away from home included eating at full service and fast food restaurants, but, as mentioned, the relationship between frequency of eating away from home and poor diet quality may vary according to restaurant type $[10,62]$. That is, food eaten at full service restaurants may differ in key nutrients from food obtained from fast food restaurants. For example, in a study of young adults, Larson and colleagues found more frequent use of full service restaurants was associated with higher vegetable and fiber consumption [10].

\subsection{Explaining the Relationship between FAFH Frequency and} FV Consumption. One of the reasons for the negative relation between FAFH frequency and FV consumption may be the lack of demand for, and thus lack of options offered of, healthy food at fast food restaurants. An Australian study found that, out of nearly 1500 meal purchases at McDonald's stores in a variety of socioeconomic areas, only $1.5 \%$ were healthy, which was defined by a symbol denoting approval from the National Heart Foundation of Australia [65]. Another study of fast food patrons found only $58 \%$ rated nutrition as 
important when buying fast food [66]. Likewise, interviews with senior menu development and marketing executives at leading casual dining and fast-food restaurant chains revealed they believe demand for healthier foods is not widespread [67]. Additional obstacles to including healthier menu items mentioned by the executives were the short shelf life of produce, increased preparation time, low sales, and high labor costs [67]. The authors noted that profit margins are the primary determinants of restaurants' choice to continue to serve healthier food options and that without an increase in consumer demand it is unlikely the restaurant industry will increase their offering of healthy food choices [67].

4.5. Results by Gender. Overall, in this study's sample, frequency of FAFH was higher among males than females. This finding is consistent with previous research $[41,68,69]$. On average, females in the current study reported eating approximately half a serving more of fruits and vegetables per day than males. This finding is also consistent with previous research [70-72].

4.6. Results by Demographic and Lifestyle Factors. In the current study, younger individuals ate out more often than older individuals, a finding supported by previous research $[24,73,74]$. In addition, individuals with higher incomes ate out more frequently. The inclusion of both cheaper and more expensive restaurants in the definition of FAFH in this study may have contributed to the finding that those with higher incomes ate out more frequently. Although eating out is generally associated with eating more unhealthful food and more calories in general, some restaurants offer healthier options and not all consumers eat more at a meal away from home compared to an at-home meal.

4.7. Recommendations. Among the recommendations in a 2006 report requested by the FDA were that food establishments should increase the availability of low-calorie menu items, provide consumers with caloric and nutrient information in a standard, easily accessible format, and develop and promote food and beverage portion size options that help consumers in their efforts to balance their energy intake and output [75].

Environmental changes may be an option. A review of worksite health promotion programs found that fruit, vegetable, and fat intake can be positively influenced by environmental strategies including labeling at the point of purchase, promotional materials, expanded availability of healthy foods, and targeted food placement [76]. In school settings, successful environmental strategies for increasing healthy food purchasing include food pricing, availability, and promotion [77]. Restaurant managers interested in promoting healthy food choices, while continuing to make a profit, could implement some of these strategies.

Other strategies concentrate more on consumers making healthy decisions when they choose to eat out. USDA recommendations include selecting water over sugar-sweetened beverages and opting for small or medium portions and dishes that have been steamed, grilled, or broiled versus fried or sautéed [78]. At fast food restaurants, recommendations include using available nutrition information to inform decisions and passing on "super-sizing" [79].

As mentioned, one reason people buy fast food is the notion that it is cheaper than home-prepared food. Articles in the popular press have attempted to refute this idea [80]. If this were true, one reason for eating away from home could be eliminated. Unfortunately, previous analyses of Seattle Obesity Study data suggest that, based on the monetary value of individual diets assessed by food frequency questionnaire, higher-cost diets were significantly higher in nutrient density $[46,81,82]$. Other studies support the finding that higher cost diets are more nutritionally dense [83-86].

4.8. Study Limitations. This study has important limitations that must be noted. First, the self-reported nature of the data for the key outcomes of interest is prone to error and bias. Next, due to the cross-sectional nature of the study, causality cannot be determined. It is possible that eating foods away from home more frequently results in higher overall calorie consumption and therefore higher BMI as well as lower fruit and vegetable intake; however, it is also possible that individuals of higher body weight and those who consumer fewer fruits and vegetables are more likely to consume away from home meals. Finally, while this was a representative sample in Seattle, Washington, these findings may not be generalizable to all U.S. cities and/or geographic regions outside the U.S.

\section{Conclusion}

In this study of 1570 adults, a positive relationship was found between FAFH and BMI in both men and women. Those who ate out more frequently tended to consume fewer fruits and vegetables, although the results were not consistent among all analyses. Overall, frequency of FAFH was higher among males than females. On average, females reported eating approximately half a serving more of fruits and vegetables per day than males. Eating out less frequently and choosing healthy, low calorie meals when away from home may help reduce overconsumption of energydense, nutrient-poor foods. Recommendations include both food establishments and consumers taking responsibility for decreasing these trends; food establishments could provide and promote healthier foods, while consumers could choose more nutrient-dense options.

\section{Abbreviations}

BMI: $\quad$ Body mass index

FAFH: Foods away from home

FV: $\quad$ Fruit and vegetable

NHANES: National Health and Nutrition Examination Survey

CSFII: Continuing Survey of Food Intakes by Individuals

BRFSS: Behavioral Risk factor Surveillance System

CARDIA: Coronary Artery Risk Development in Young Adults

SES: $\quad$ Socioeconomic status. 


\section{Disclosure}

The National Institutes of Health and the National Institute of Diabetes and Digestive and Kidney Diseases had no role in the design, collection, analysis, or interpretation of data or writing of this paper.

\section{Conflict of Interests}

Adam Drewnowski has received grants, contracts, honoraria, and consulting fees from numerous food and beverage companies, restaurant industry, and other commercial and nonprofit entities with interests in diet quality and health. The University of Washington has received grants, donations, and contracts from both the public and the private sector. Rebecca A. Seguin, Anju Aggarwal, and Francoise Vermeylen declare that they have no competing interests.

\section{Authors' Contribution}

Rebecca A. Seguin, Anju Aggarwal, and Adam Drewnowski formulated the research questions and designed and carried out the study. Rebecca A. Seguin and Francoise Vermeylen analyzed the data. All authors contributed to the writing of the paper and approved the final version of the paper.

\section{Acknowledgments}

This work was supported by the National Institutes of Health (Rebecca A. Seguin, K01HL108807) and the National Institute of Diabetes and Digestive and Kidney Diseases (Anju Aggarwal and Adam Drewnowski, RO1DK076608).

\section{References}

[1] J. F. Guthrie, B.-H. Lin, and E. Frazao, "Role of food prepared away from home in the American diet, 1977-78 versus 1994-96: changes and consequences," Journal of Nutrition Education and Behavior, vol. 34, no. 3, pp. 140-150, 2002.

[2] L. M. Powell, B. T. Nguyen, and E. Han, "Energy intake from restaurants: demographics and socioeconomics, 2003-2008," American Journal of Preventive Medicine, vol. 43, no. 5, pp. 498504, 2012.

[3] J. M. Poti and B. M. Popkin, "Trends in energy intake among US children by eating location and food source, 1977-2006," Journal of the American Dietetic Association, vol. 111, no. 8, pp.1156-1164, 2011.

[4] B.-H. Lin and J. Guthrie, "Nutritional quality of food prepared at home and away from home, 1977-2008," in Book Nutritional Quality of Food Prepared at Home and away from Home, 19772008, vol. EIB-105, Economic Research Service, Washington, DC, USA, 2012.

[5] H. M. Aljadani, A. Patterson, D. Sibbritt, M. J. Hutchesson, M. E. Jensen, and C. E. Collins, "Diet quality, measured by fruit and vegetable intake, predicts weight change in young women," Journal of Obesity, vol. 2013, Article ID 525161, 10 pages, 2013.

[6] C. E. O’Neil, T. A. Nicklas, and V. L. Fulgoni III, “Consumption of apples is associated with a better diet quality and reduced risk of obesity in children: National Health and Nutrition Examination Survey (NHANES) 2003-2010," Nutrition Journal, vol. 14, article 48, 2015.
[7] Z. Bahadoran, P. Mirmiran, M. Golzarand, F. HosseiniEsfahani, and F. Azizi, "Fast food consumption in Iranian adults; dietary intake and cardiovascular risk factors: Tehran Lipid and Glucose Study," Archives of Iranian Medicine, vol. 15, no. 6, pp. 340-341, 2012.

[8] E. R. Fowles, G. M. Timmerman, M. Bryant, and S. Kim, "Eating at fast-food restaurants and dietary quality in low-income pregnant women," Western Journal of Nursing Research, vol. 33, no. 5, pp. 630-651, 2011.

[9] S. A. French, M. Story, D. Neumark-Sztainer, J. A. Fulkerson, and P. Hannan, "Fast food restaurant use among adolescents: associations with nutrient intake, food choices and behavioral and psychosocial variables," International Journal of Obesity, vol. 25, no. 12, pp. 1823-1833, 2001.

[10] N. Larson, D. Neumark-Sztainer, M. N. Laska, and M. Story, "Young adults and eating away from home: associations with dietary intake patterns and weight status differ by choice of restaurant," Journal of the American Dietetic Association, vol. 111, no. 11, pp. 1696-1703, 2011.

[11] J. A. Satia, J. A. Galanko, and A. M. Siega-Riz, "Eating at fastfood restaurants is associated with dietary intake, demographic, psychosocial and behavioural factors among African Americans in North Carolina," Public Health Nutrition, vol. 7, no. 8, pp. 1089-1096, 2004.

[12] J. E. Todd, L. Mancino, and B.-H. Lin, "The impact of food away from home on adult diet quality," Economic Research Report ERR-90, United States Department of Agriculture, 2010.

[13] P. M. Guenther, K. O. Casavale, J. Reedy et al., "Update of the Healthy Eating Index: HEI-2010," Journal of the Academy of Nutrition and Dietetics, vol. 113, no. 4, pp. 569-580, 2013.

[14] L. Mancino, J. Todd, and B.-H. Lin, "Separating what we eat from where: measuring the effect of food away from home on diet quality," Food Policy, vol. 34, no. 6, pp. 557-562, 2009.

[15] S. A. Bowman and B. T. Vinyard, "Fast food consumption of U.S. adults: impact on on energy and nutrient intakes and overweight status," Journal of the American College of Nutrition, vol. 23, no. 2, pp. 163-168, 2004.

[16] M. A. McCrory, P. J. Fuss, N. P. Hays, A. G. Vinken, A. S. Greenberg, and S. B. Roberts, "Overeating in America: association between restaurant food consumption and body fatness in healthy adult men and women ages 19 to 80," Obesity Research, vol. 7, no. 6, pp. 564-571, 1999.

[17] L. M. Powell and B. T. Nguyen, "Fast-food and full-service restaurant consumption among children and adolescents: effect on energy, beverage, and nutrient intake," JAMA Pediatrics, vol. 167, no. 1, pp. 14-20, 2013.

[18] G. X. Ayala, M. Rogers, E. M. Arredondo et al., "Away-fromhome food intake and risk for obesity: examining the influence of context," Obesity, vol. 16, no. 5, pp. 1002-1008, 2008.

[19] H. Schröder, M. Fito, and M. I. Covas, "Association of fast food consumption with energy intake, diet quality, body mass index and the risk of obesity in a representative Mediterranean population," British Journal of Nutrition, vol. 98, no. 6, pp. 12741280, 2007.

[20] K. J. Duffey, P. Gordon-Larsen, D. R. Jacobs Jr., O. D. Williams, and B. M. Popkin, "Differential associations of fast food and restaurant food consumption with 3-y change in body mass index: the Coronary Artery Risk Development in Young Adults Study," The American Journal of Clinical Nutrition, vol. 85, no. 1, pp. 201-208, 2007. 
[21] A. K. Kant and B. I. Graubard, "Eating out in America, 19872000: trends and nutritional correlates," Preventive Medicine, vol. 38, no. 2, pp. 243-249, 2004.

[22] I. N. Bezerra and R. Sichieri, "Eating out of home and obesity: a Brazilian nationwide survey," Public Health Nutrition, vol. 12, no. 11, pp. 2037-2043, 2009.

[23] I. N. Bezerra, C. Curioni, and R. Sichieri, "Association between eating out of home and body weight," Nutrition Reviews, vol. 70, no. 2, pp. 65-79, 2012.

[24] B. Anderson, A. P. Rafferty, S. Lyon-Callo, C. Fussman, and G. Imes, "Fast-food consumption and obesity among michigan adults," Preventing Chronic Disease, vol. 8, no. 4, 2011.

[25] A. Naska, P. Orfanos, A. Trichopoulou et al., "Eating out, weight and weight gain. A cross-sectional and prospective analysis in the context of the EPIC-PANACEA study," International Journal of Obesity, vol. 35, no. 3, pp. 416-426, 2011.

[26] S. Krishnan, P. F. Coogan, D. A. Boggs, L. Rosenberg, and J. R. Palmer, "Consumption of restaurant foods and incidence of type 2 diabetes in African American women," The American Journal of Clinical Nutrition, vol. 91, no. 2, pp. 465-471, 2010.

[27] M. Bes-Rastrollo, F. J. Basterra-Gortari, A. Snchez-Villegas, A. Marti, J. A. Martnez, and M. A. Martnez-González, "A prospective study of eating away-from-home meals and weight gain in a Mediterranean population: the SUN (Seguimiento Universidad de Navarra) cohort," Public Health Nutrition, vol. 13, no. 9, pp. 1356-1363, 2010.

[28] O. M. Thompson, C. Ballew, K. Resnicow et al., "Food purchased away from home as a predictor of change in BMI z-score among girls," International Journal of Obesity, vol. 28, no. 2, pp. 282-289, 2004.

[29] L. J. Gillis and O. Bar-Or, "Food away from home, sugarsweetened drink consumption and juvenile obesity," Journal of the American College of Nutrition, vol. 22, no. 6, pp. 539-545, 2003.

[30] Y. S. Ma, E. R. Bertone, E. J. Stanek III et al., "Association between eating patterns and obesity in a free-living US adult population," American Journal of Epidemiology, vol. 158, no. 1, pp. 85-92, 2003.

[31] R. M. Viner and T. J. Cole, "Who changes body mass between adolescence and adulthood? Factors predicting change in BMI between 16 year and 30 years in the 1970 British Birth Cohort," International Journal of Obesity, vol. 30, no. 9, pp. 1368-1374, 2006.

[32] H. Croker, R. M. Viner, D. Nicholls et al., "Family-based behavioural treatment of childhood obesity in a UK national health service setting: randomized controlled trial," International Journal of Obesity, vol. 36, no. 1, pp. 16-26, 2012.

[33] G. Garcia, T. S. Sunil, and P. Hinojosa, "The fast food and obesity link: consumption patterns and severity of obesity," Obesity Surgery, vol. 22, no. 5, pp. 810-818, 2012.

[34] L. K. Fraser, G. P. Clarke, J. E. Cade, and K. L. Edwards, "Fast food and obesity: a spatial analysis in a large United Kingdom population of children aged 13-15," American Journal of Preventive Medicine, vol. 42, no. 5, pp. e77-e85, 2012.

[35] A. O. Odegaard, W. P. Koh, J.-M. Yuan, M. D. Gross, and M. A. Pereira, "Western-style fast food intake and cardiometabolic risk in an Eastern country," Circulation, vol. 126, no. 2, pp. 182$188,2012$.

[36] J. A. Fulkerson, K. Farbakhsh, L. Lytle et al., "Away-from-home family dinner sources and associations with weight status, body composition, and related biomarkers of chronic disease among adolescents and their parents," Journal of the American Dietetic Association, vol. 111, no. 12, pp. 1892-1897, 2011.

[37] H. M. Niemeier, H. A. Raynor, E. E. Lloyd-Richardson, M. L. Rogers, and R. R. Wing, "Fast food consumption and breakfast skipping: predictors of weight gain from adolescence to adulthood in a nationally representative sample," Journal of Adolescent Health, vol. 39, no. 6, pp. 842-849, 2006.

[38] T. S. Ferguson, M. K. Tulloch-Reid, N. O. Younger et al., "Fast food consumption significantly increases risk of hypercholesterolemia among Afro-Caribbean youth in Jamaica," Circulation, vol. 124, Article ID A10135, 2011.

[39] K. J. Smith, S. A. McNaughton, S. L. Gall, L. Blizzard, T. Dwyer, and A. J. Venn, "Takeaway food consumption and its associations with diet quality and abdominal obesity: a crosssectional study of young adults," International Journal of Behavioral Nutrition and Physical Activity, vol. 6, article 29, 2009.

[40] M. Liebman, S. Pelican, S. A. Moore et al., "Dietary intake, eating behavior-, and physical activity-related determinants of high body mass index in the 2003 Wellness IN the Rockies cross-sectional study," Nutrition Research, vol. 26, no. 3, pp. 111117, 2006.

[41] M. A. Pereira, A. I. Kartashov, C. B. Ebbeling et al., "Fast-food habits, weight gain, and insulin resistance (the CARDIA study): 15-year prospective analysis," The Lancet, vol. 365, no. 9453, pp. 36-42, 2005.

[42] K. J. Smith, L. Blizzard, S. A. McNaughton, S. L. Gall, T. Dwyer, and A. J. Venn, "Takeaway food consumption and cardiometabolic risk factors in young adults," European Journal of Clinical Nutrition, vol. 66, no. 5, pp. 577-584, 2012.

[43] K. J. Tobin, "Fast-food consumption and educational test scores in the USA," Child: Care, Health and Development, vol. 39, no. 1, pp. 118-124, 2013.

[44] R. Patterson, A. Risby, and M.-Y. Chan, "Consumption of takeaway and fast food in a deprived inner London Borough: are they associated with childhood obesity?" BMJ Open, vol. 2, no. 3, Article ID e000402, 2012.

[45] A. Drewnowski, A. Aggarwal, P. M. Hurvitz, P. Monsivais, and A. V. Moudon, "Obesity and supermarket access: proximity or price?" American Journal of Public Health, vol. 102, no. 8, pp. e74-e80, 2012.

[46] A. Aggarwal, P. Monsivais, A. J. Cook, and A. Drewnowski, "Does diet cost mediate the relation between socioeconomic position and diet quality?" European Journal of Clinical Nutrition, vol. 65, no. 9, pp. 1059-1066, 2011.

[47] E. Isganaitis and R. H. Lustig, "Fast food, central nervous system insulin resistance, and obesity," Arteriosclerosis, Thrombosis, and Vascular Biology, vol. 25, no. 12, pp. 2451-2462, 2005.

[48] P. Orfanos, A. Naska, A. Trichopoulou et al., "Eating out of home: energy, macro- and micronutrient intakes in 10 European countries. the European Prospective Investigation into Cancer and Nutrition," European Journal of Clinical Nutrition, vol. 63, no. 4, pp. S239-S262, 2009.

[49] L. R. Young and M. Nestle, "The contribution of expanding portion sizes to the US obesity epidemic," American Journal of Public Health, vol. 92, no. 2, pp. 246-249, 2002.

[50] N. Diliberti, P. L. Bordi, M. T. Conklin, L. S. Roe, and B. J. Rolls, "Increased portion size leads to increased energy intake in a restaurant meal," Obesity Research, vol. 12, no. 3, pp. 562-568, 2004.

[51] D. A. Levitsky and T. Youn, "The more food young adults are served, the more they overeat," Journal of Nutrition, vol. 134, no. 10, pp. 2546-2549, 2004. 
[52] B. J. Rolls, E. L. Morris, and L. S. Roe, "Portion size of food affects energy intake in normal-weight and overweight men and women," American Journal of Clinical Nutrition, vol. 76, no. 6, pp. 1207-1213, 2002.

[53] B. J. Rolls, L. S. Roe, J. S. Meengs, and D. E. Wall, "Increasing the portion size of a sandwich increases energy intake," Journal of the American Dietetic Association, vol. 104, no. 3, pp. 367-372, 2004.

[54] B. J. Rolls, L. S. Roe, and J. S. Meengs, "Larger portion sizes lead to a sustained increase in energy intake over 2 days," Journal of the American Dietetic Association, vol. 106, no. 4, pp. 543-549, 2006.

[55] R. W. Jeffery, S. Rydell, C. L. Dunn et al., "Effects of portion size on chronic energy intake," International Journal of Behavioral Nutrition and Physical Activity, vol. 4, article 27, 2007.

[56] M. T. Kelly, J. M. W. Wallace, P. J. Robson et al., "Increased portion size leads to a sustained increase in energy intake over $4 \mathrm{~d}$ in normal-weight and overweight men and women," British Journal of Nutrition, vol. 102, no. 3, pp. 470-477, 2009.

[57] J. M. de Castro, G. A. King, M. Duarte-Gardea, S. GonzalezAyala, and C. H. Kooshian, "Overweight and obese humans overeat away from home," Appetite, vol. 59, no. 2, pp. 204-211, 2012.

[58] C. M. Devine, "A life course perspective: understanding food choices in time, social location, and history," Journal of Nutrition Education and Behavior, vol. 37, no. 3, pp. 121-128, 2005.

[59] T. Furst, M. Connors, C. A. Bisogni, J. Sobal, and L. W. Falk, "Food choice: a conceptual model of the process," Appetite, vol. 26, no. 3, pp. 247-265, 1996.

[60] P. Monsivais, A. Aggarwal, and A. Drewnowski, "Time spent on home food preparation and indicators of healthy eating," American Journal of Preventive Medicine, vol. 47, no. 6, pp. 796802, 2014.

[61] J. A. Wolfson and S. N. Bleich, "Is cooking at home associated with better diet quality or weight-loss intention?" Public Health Nutrition, vol. 18, no. 8, pp. 1397-1406, 2015.

[62] C. Befort, H. Kaur, N. Nollen et al., "Fruit, vegetable, and fat intake among non-Hispanic black and non-Hispanic white adolescents: associations with home availability and food consumption settings," Journal of the American Dietetic Association, vol. 106, no. 3, pp. 367-373, 2006.

[63] M. K. Choi, T. Y. Kim, and J.-S. Yoon, "Does frequent eating out cause undesirable food choices? Association of food away from home with food consumption frequencies and obesity among Korean housewives," Ecology of Food and Nutrition, vol. 50, no. 3, pp. 263-280, 2011.

[64] M. S. Lee and S. Kim, "The influence of health-related habits on nutrient intake and food frequency of middle-aged subjects in Seoul," Korean Journal of Community Nutrition, vol. 8, pp. 699707, 2003.

[65] L. Wellard, C. Glasson, and K. Chapman, "Sales of healthy choices at fast food restaurants in Australia," Health Promotion Journal of Australia, vol. 23, no. 1, pp. 37-41, 2012.

[66] M. O’Dougherty, L. J. Harnack, S. A. French, M. Story, J. M. Oakes, and R. W. Jeffery, "Nutrition labeling and value size pricing at fast-food restaurants: a consumer perspective," American Journal of Health Promotion, vol. 20, no. 4, pp. 247250, 2006.

[67] K. Glanz, K. Resnicow, J. Seymour et al., "How major restaurant chains plan their menus-the role of profit, demand, and health," American Journal of Preventive Medicine, vol. 32, no. 5, pp. 383-388, 2007.
[68] L. V. Moore, A. V. D. Roux, J. A. Nettleton, D. R. Jacobs, and M. Franco, "Fast-Food consumption, diet quality, and neighborhood exposure to fast food," American Journal of Epidemiology, vol. 170, no. 1, pp. 29-36, 2009.

[69] J. Boone-Heinonen, P. Gordon-Larsen, C. I. Kiefe, J. M. Shikany, C. E. Lewis, and B. M. Popkin, "Fast food restaurants and food stores longitudinal associations with diet in young to middleaged adults: the CARDIA study," Archives of Internal Medicine, vol. 171, no. 13, pp. 1162-1170, 2011.

[70] A. H. Baker and J. Wardle, "Sex differences in fruit and vegetable intake in older adults," Appetite, vol. 40, no. 3, pp. 269-275, 2003.

[71] M. Dehghan, N. Akhtar-Danesh, and A. T. Merchant, "Factors associated with fruit and vegetable consumption among adults," Journal of Human Nutrition and Dietetics, vol. 24, no. 2, pp. 128 134, 2011.

[72] M. Rasmussen, R. Krølner, K.-I. Klepp et al., "Determinants of fruit and vegetable consumption among children and adolescents: a review of the literature. Part I: quantitative studies," International Journal of Behavioral Nutrition and Physical Activity, vol. 3, article 22, 2006.

[73] J. M. Dave, L. C. An, R. W. Jeffery, and J. S. Ahluwalia, "Relationship of attitudes toward fast food and frequency of fast-food intake in adults," Obesity, vol. 17, no. 6, pp. 1164-1170, 2009.

[74] K. van der Horst, T. A. Brunner, and M. Siegrist, "Fast food and take-away food consumption are associated with different lifestyle characteristics," Journal of Human Nutrition and Dietetics, vol. 24, no. 6, pp. 596-602, 2011.

[75] Keyston Center, The Keystone Forum on Away-from-Home Foods: Opportunities for Preventing Weight Gain and Obesity: Final Report, Keyston Center, 2006.

[76] L. H. Engbers, M. N. M. van Poppel, M. J. M. C. A. Paw, and W. van Mechelen, "Worksite health promotion programs with environmental changes-a systematic review," American Journal of Preventive Medicine, vol. 29, no. 1, pp. 61-70, 2005.

[77] S. A. French, "Public health strategies for dietary change: schools and workplaces," Journal of Nutrition, vol. 135, no. 4, pp. 910-912, 2005.

[78] Tips for Eating Healthy When Eating Out, http://www.choosemyplate.gov/healthy-eating-tips/tips-for-eating-out.html.

[79] Eating Fast Food, http://www.heart.org/HEARTORG/GettingHealthy/NutritionCenter/DiningOut/Eating-Fast-Food_UCM_ 301473_Article.jsp.

[80] M. Bittman, Is Junk Food Really Cheaper?, 2011.

[81] P. Monsivais, A. Aggarwal, and A. Drewnowski, "Are socioeconomic disparities in diet quality explained by diet cost?" Journal of Epidemiology and Community Health, vol. 66, no. 6, pp. 530-535, 2012.

[82] P. Monsivais, A. Aggarwal, and A. Drewnowski, "Following federal guidelines to increase nutrient consumption may lead to higher food costs for consumers," Health Affairs, vol. 30, no. 8, pp. 1471-1477, 2011.

[83] C. D. Rehm, P. Monsivais, and A. Drewnowski, "The quality and monetary value of diets consumed by adults in the United States," The American Journal of Clinical Nutrition, vol. 94, no. 5, pp. 1333-1339, 2011.

[84] M. Maillot, N. Darmon, F. Vieux, and A. Drewnowski, "Low energy density and high nutritional quality are each associated with higher diet costs in French adults," American Journal of Clinical Nutrition, vol. 86, no. 3, pp. 690-696, 2007. 
[85] A. Drewnowski, P. Monsivais, M. Maillot, and N. Darmon, "Low-energy-density diets are associated with higher diet quality and higher diet costs in French adults," Journal of the American Dietetic Association, vol. 107, no. 6, pp. 1028-1032, 2007.

[86] E. Andrieu, N. Darmon, and A. Drewnowski, "Low-cost diets: more energy, fewer nutrients," European Journal of Clinical Nutrition, vol. 60, no. 3, pp. 434-436, 2006. 


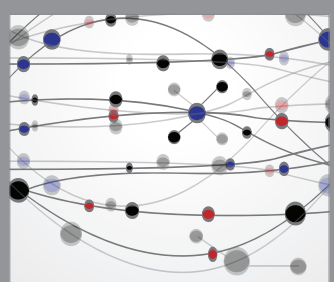

The Scientific World Journal
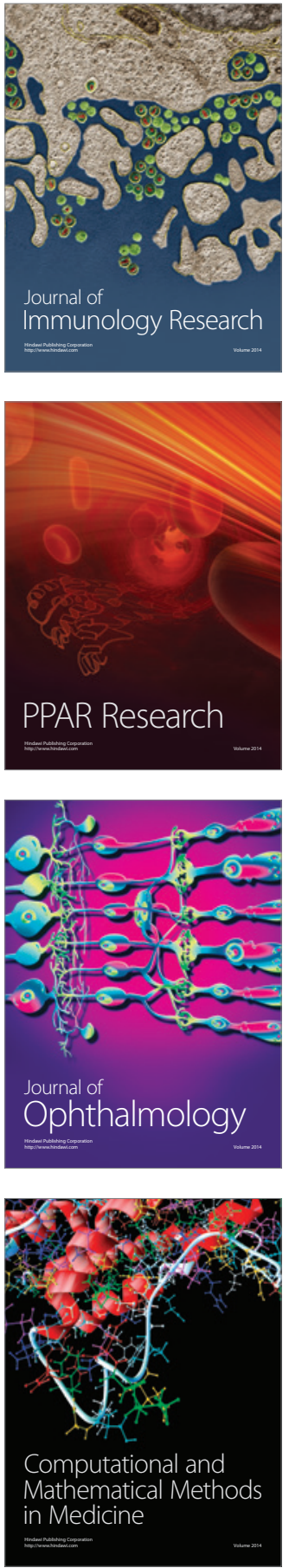

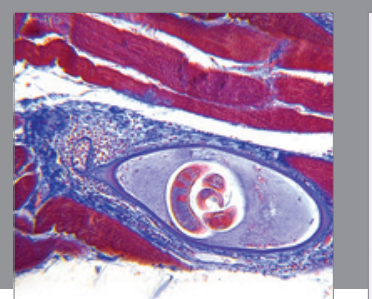

Gastroenterology Research and Practice

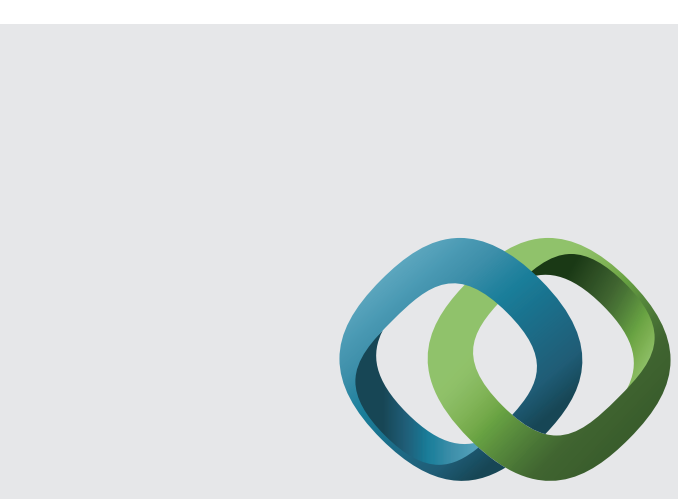

\section{Hindawi}

Submit your manuscripts at

http://www.hindawi.com
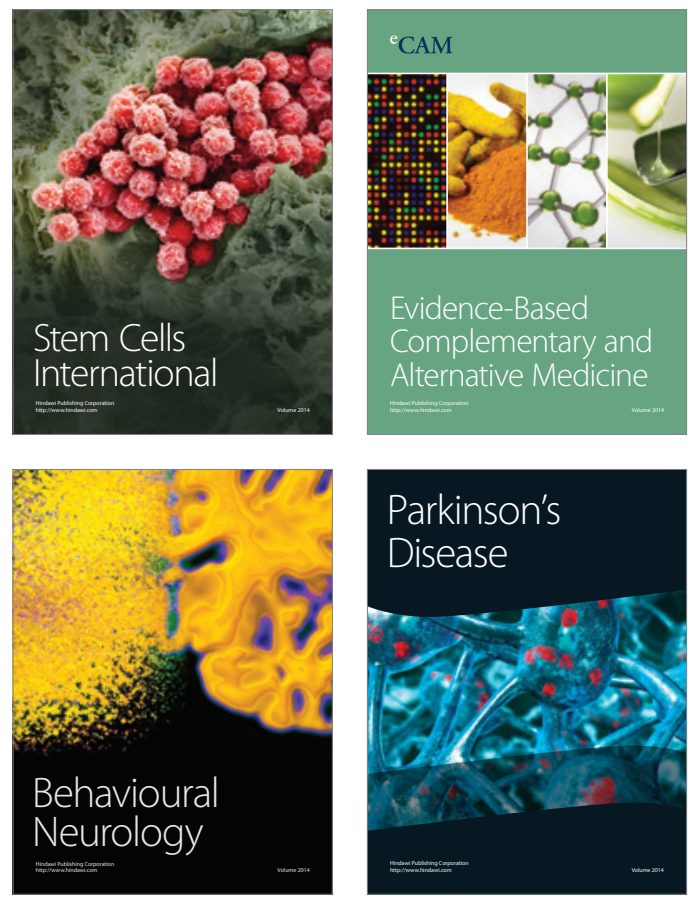
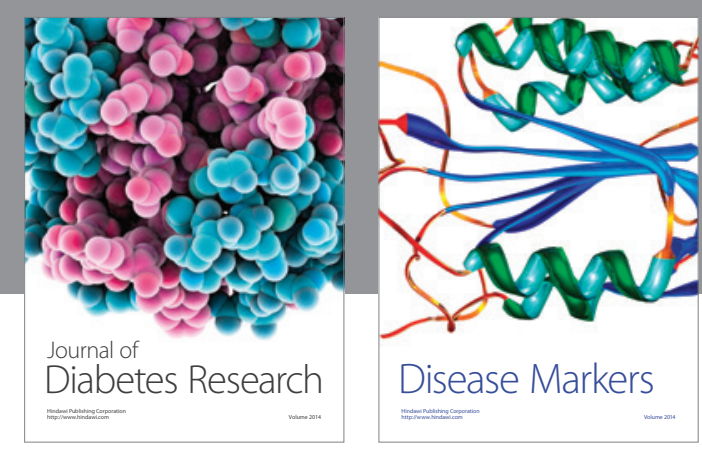

Disease Markers
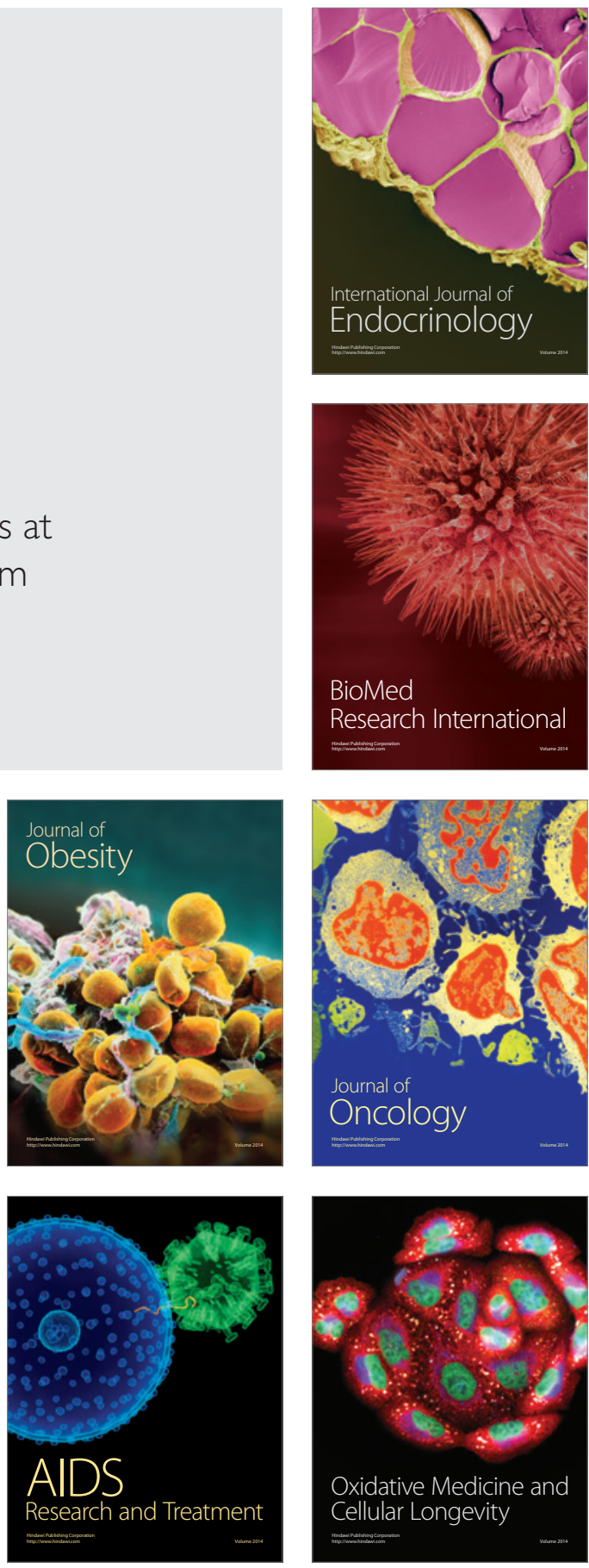